\title{
LA FILOSOFIA ANDALUSÍ FRENTE AL SUFISMO
}

\author{
EMILIO TORNERO \\ Universidad Complutense
}

\begin{abstract}
La metafísica o el intento de concebir el mundo como un todo por medio del pensamiento se ha desarrollado desde el principio gracias a la unión y al conflicto entre dos impulsos humanos muy diferentes, uno que llevaba a los hombres hacia el misticismo y otro que los llevaba hacia la ciencia...

Pero los hombres más eminentes que han sido filósofos han sentido la necesidad tanto de la ciencia como del misticismo: el intento de armonizar los dos fue lo que constituyó y siempre deberá constituir su vida, ya que su ardua incertidumbre hace de la filosofía, para algunos espiritus, algo más grande que la ciencia o la religión ${ }^{1}$.
\end{abstract}

Estas afirmaciones de B. Russell pueden ser corroboradas en el caso de la filosofía andalusí, pues sus tres grandes figuras filosóficas, Avempace, Ibn Țufayl y Averroes, como trataré de hacer ver, muestran una gran preocupación por el alcance y la validez de la vía sufí en relación con la vía filosófica. Preocupación que venía previamente motivada por el reto del sufismo a la filosofía al proponer éste una nueva y más certera vía para obtener el conocimiento y la felicidad del hombre, haciendo inútil, por consiguiente, a la filosofía en su doble vertiente de teoría y praxis.

Doctrina común del sufismo es su reivindicación de una inspiración divina, ilhām, similar a la del profeta, wahy, a través de la que se obtiene el conocimiento de una manera instantánea y sin esfuerzo humano. Este conocimiento es considerado por el sufismo como superior al conocimiento especulativo y es descrito por los sufíes como un dawq, gustación, término de raigambre neoplatónica, con el que se designa el primer grado de la unión extática, unión que proporciona un saber y una felicidad muy superior, la máxima que el hombre puede conseguir.

1 Russell, B., «Misticismo y lógica» en su obra Misticismo y lógica y otros ensayos, Barcelona, 1987, 21. 
Para el sufismo es, pues, la filosofía algo ocioso e inútil, relegada a aquellos que no pueden ascender a las alturas del éxtasis sufí, y es contemplada, en todo caso, con aires de condescendencia, ya que el saber y la felicidad que puede proporcionar es de índole muy inferior.

El reto del sufismo a la filosofía fue reforzado con un andamiaje intelectual y sistemático por Algazel y será a él, sobre todo, a quien van a tener presente los filósofos andalusíes en esta confrontación. Las actitudes de éstos frente al sufismo podemos caracterizarlas, brevemente, del siguiente modo:

Avempace niega totalmente la validez de la vía sufí. El conocimiento y la felicidad sólo pueden obtenerse por la filosofía. Filosofía, la suya, muy racionalista a la que dota de tales características que, en cierto modo, hace de ella una vía mística sustitutiva del sufismo.

Ibn Țufayl asume la vía sufí dentro de su filosofía, aunando el éxtasis buscado por los sufíes con el éxtasis plotiniano.

Averroes reconoce la validez de la vía sufí, pero sólo para unos pocos selectos. La vía normal, la accesible al hombre inteligente y esforzado, para conseguir el conocimiento y la felicidad, es la filosofía. Filosofía en la que la experiencia del éxtasis no es contemplada.

\section{Avempace}

Hay en la obra de Avempace un enfrentamiento explícito con los sufíes en el que éste defiende ardorosamente el quehacer filosófico frente a las pretensiones de aquéllos y en donde trata también, a su vez, de mostrar la inanidad de la vía sufí.

Para Avempace el hombre sólo se realiza como hombre y es máximamente feliz cuando tiene lugar su actividad especulativa, cuando raciocina. Aunque coincide en este intelectualismo con Aristóteles, la actividad noética la entiende, sin embargo, Avempace, más de un modo neoplatónico, como un progresivo prescindir de la materia y de los sentidos, pero sin llegar nunca, por lo demás, a un tipo de conocimiento distinto o superior al discursivo o racional. Tampoco tenemos mención en Avempace de una emanación de pensamientos directamente del Intelecto Activo ${ }^{2}$. No hay nada más allá de la facultad discursiva del

2 Cfr. Davidson, H. A., Alfarabi, Avicenna and Averroes on Intellect. Their cosmologies, theories of the Active Intellect, and theories of the human Intellect, New York-Oxford, $1992,145$. 
hombre de donde le pueda provenir a éste el conocimiento y la felicidad que el conocer conlleva. Al ejercer su actividad cognoscitiva se produce en él la unión con el Intelecto Activo, según observa Averroes criticándole precisamente esto mismo ${ }^{3}$.

En esta unión conseguida, pues, exclusivamente gracias a la actividad humana llega el hombre a la máxima cercanía a Dios, ya que el Intelecto Activo es la más cercana de las criaturas a Dios y por ello es el hombre muy superior al resto de los seres, tanto que Avempace llega a calificarlo de divino:

Por la corporeidad es, pues, el hombre simplemente un ser; más por la espiritualidad es ya un ser más noble; y por la intelectualidad es un ser divino y virtuoso ${ }^{4}$.

Y sin proponérselo como fin, puesto que su único objetivo es el conocer la verdad, consigue el hombre mediante esta actividad su felicidad. El único deleite continuo y perpetuo, dice, es el del entendimiento adquirido 5 .

La índole de esta felicidad es puramente intelectual, alejada de todo contacto con el mundo sensible, y Avempace llega a igualarla con la felicidad escatológica:

La mirada intelectual o especulativa... constituye la vida futura y la sola felicidad última humana ${ }^{6}$.

Desde esta concepción, tan intelectual, acusa a los sufíes de un craso sensualismo, pues dice que éstos, incapaces de percibir las formas espirituales puras, las perciben mezcladas con la materia, y por ello, su

3 "non quod intelligere invenitur in nobis postquam non erat, quod est causa in continuatione intellectus agentis nobiscum, ut intendebat Avempeche, sed causa intellectionis est continuatio, et non e contrarion, en Averrois Cordubensis commentarium magnum in Aristotelis. De anima libros, ed. F. S. Grawford, Cambridge, Mass., Medieval Academy of America, 1953, 501.

4 Avempace, El régimen del solitario, ed. y trad. de M. Asín Palacios, Madrid-Granada, 1946, 100 trad.; 61 texto árabe. Siguiendo a Aristóteles, Ética Nicomáquea, 1177a$1178 \mathrm{a}$.

5 Cfr. Asín Palacios, M., "La "carta de adiós“ de Avempace», Al-Andalus, VIII (1943), 69 trad.; 30 texto árabe.

6 Cfr. Asín Palacios, M., "Tratado de Avempace sobre la unión del intelecto con el hombre", Al-Andalus, VII (1942), 38 trad.; 17 texto árabe. 
percepción es como si esas formas fuesen realmente sentidas, mahsūsa, esto es, percibidas por los sentidos:

Y por eso... preséntase la forma espiritual como si fuese realmente sentida... los sufíes, incapaces de percibir las formas espirituales puras... ${ }^{7}$.

Este sensualismo lleva a los sufíes a buscar incluso un placer sensible en el conocimiento de la verdad y, así, dice de Algazel que si éste trata de contemplar el mundo inteligible, si busca el conocimiento de la verdad, no es por la verdad misma. Su fin no es la verdad sino el deleite sensible que su conocimiento produce:

supone (Algazel) que el fin último es la contemplación del mundo inteligible... y el deleitarse con las maravillas que el hombre ve en ese mundo... da a entender que el fin último del conocimiento de la verdad es el delei-

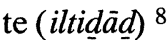

7 Cfr. Asín, M., El régimen, 58-59 trad.; 27 texto árabe.

8 Cfr. Asín, M., "La "carta de adiós"», 58 trad.; 22 texto árabe.

Esta censura de Avempace del sensualismo y delectación de los sufíes es citada también por Ibn Tufayl en el Prólogo que antepuso a El filósofo autodidacto. Cfr. Hayy ben Yaqdhân. Roman philosophique d'Ibn Thofail, texte arabe... et traduction française, $2^{\mathrm{e}}$ édition... par Leon Gauthier, Beirut, Imprimerie Catholique, 1936, 10 texto árabe. Véase su traducción castellana en Ibn Țufayl, El filósofo autodidacto, Madrid, 1995, 35.

Más que a Algazel, que, siguiendo una línea neoplatónica, se muestra partidario de un sufismo depurado de todo contacto con el cuerpo y sus sentidos, hay que aplicar estos juicios de Avempace a sectores populares del sufismo que conciben tanto el éxtasis como los goces escatológicos de una manera corporal y sensual, muy de acuerdo, por otro lado, con la "ortodoxia" islámica.

En este sentido observa P. Nwya, Exégèse coranique et langage mystique, Beirut, Dar el Mashreq, 1970, 107, a propósito de las ideas escatológicas de al-Muhāsibī, que no es exacto entender sus alegorías corporales como referidas sólo a una visión pura de la esencia divina, sino que este místico integra ambas realidades, las espirituales y las corporales. Ilustraciones de este sensualismo tenemos, por ejemplo, en al-Ŷilì, al-Manäzir al-ilähiyya, El Cairo, Dār al-Manār, 1407/1987, 117, donde se relata el caso de un sufí que, vuelto en sí del trance extático, se encontró con que había eyaculado, como consecuencia corporal del intenso placer espiritual que había sentido, y en pp. 200-201 comenta al-Ŷilì que, cuando Dios se manifiesta a sus adoradores, les sobreviene a éstos un desmayo por la intensidad del placer que experimentan, placer que es calificado, literalmente, de sensible (ladda mahsüsa).

Este situar la felicidad fuera de la esfera intelectual, en directa confrontación con Aristóteles, lo tenemos en el filósofo judío Hasday Crescas, para quien la felicidad y la alegría provienen de la esfera de la sensibilidad y de la voluntad. La perfección del hombre no consiste en su perfección intelectual, sino en su unión con Dios. Para este pensador el centro de la vida de Dios no es el pensamiento sino la bondad, y su felicidad no 
Refuta también Avempace la otra pretensión de los sufíes, la de que se puede prescindir del estudio, del esfuerzo especulativo, para la consecución de la felicidad última, que es, pues, la que proviene del conocimiento de la verdad. Y es que el objetivo de éstos, dice Avempace, no es precisamente el conocer, sino todo lo contrario, vaciar el entendimiento:

Pretenden los sufíes que la felicidad última se alcanza sin estudio y, más todavía, con el vacío del entendimiento, de modo que ni un solo momento deja de tenerse presente el recuerdo de lo tenebroso ( $\mathrm{d} i \mathrm{kr}$ almažlüm) ${ }^{9}$.

Frente al proceso de iluminación creciente en que consiste el conocimiento, los sufíes, dice Avempace, proponen el recuerdo, la mención de lo tenebroso, expresión con la que Avempace parece aludir a la conocida práctica sufí de la mención continua del nombre de Dios, dikr Allāh, sólo que en lugar de Allāh, Avempace ha puesto lo de «tenebroso", mažlüm, subrayando la oscuridad buscada por los sufíes, en vez de la luz del entendimiento que él propone, pues según comenta en otro lugar, lo propio del hombre es salir de la oscuridad, zulma, propia del animal irracional, $y$, pasando por las distintas gradaciones de sombra, zill, propia del animal racional, llegar a la luz del entendimiento ${ }^{10}$.

La descripción de la felicidad embriagadora que produce el éxtasis sufí es aplicada por Avempace a la que produce el conocimiento discursivo del hombre, del filósofo, una vez llegado a su culmen, de tal modo que Avempace parece hacer de la filosofía una especie de mística alternativa a la vía del sufismo ${ }^{11}$.

En el alma apetitiva nace, en tal grado, un estado psíquico semejante al temor reverencial y parecido en cierto modo al estado de ánimo que

consiste en conocerse a sí misno, pues si del conocimiento procede alguna felicidad proviene ésta, en todo caso, de su adquisición, no de su posesión. Cfr. Waxman, M., The Philosophy of Don Hasdai Crescas, New York, Columbia University Press, 1920, pp. 7576.

Que la sensibilidad, el serısualismo, la reivindicación del cuerpo, es la esencia de la religión, es una afirmación de L. Feuerbach a propósito del Cristianismo. Cfr. A. Schmidt, Feuerbach o la sensualidad emancipada, Madrid, 1975, donde se estudia este tema y sus implicaciones filósoficas en Feuerbach.

9 Avempace, El régimen, 59 trad.; 27 texto árabe.

10 Cfr., Asín, M., "La "carta de adiós“", 81 trad.; 36-37 texto árabe.

11 Lomba, J., Avempace, Zaragoza, 1989, 13, habla de un "racionalismo místico" o de una "mística racionalista» en Avempace. 
sobreviene al ver algo grandioso y bello; ese estado de alma se llama estupefacción. Los sufíes extreman las hipérboles al describir tal estado... que se parece a la emoción de alegría extremada que siente el que está orgulloso de poseer algo en cuya comparación todas las cosas le son ya despreciables 12 .

En lugar de la vía sufí, Avempace propone, por tanto, la vía filosófica como la única vía capaz de dar al hombre satisfacción cumplida de todo aquello que buscan los sufíes.

El filósofo, el amante de la verdad, es denominado por Avempace, mutawaḥhid, solitario, término con que es denominado también el sufí, por ejemplo, en al-Kalābādīi ${ }^{13}$. Expresamente dice Avempace, comparando, que:

estos solitarios son los que los sufíes designan con el sobrenombre de "extranjeros" gurabä,. 14

Para estos "solitarios» compuso Avempace una especie de Regla, su conocida obra Tadbir al-mutawaḥhid (El régimen del solitario). Tadbir que incluye la regulación y dirección de ese esfuerzo humano, de ese estudio, necesario para la consecución del conocimiento de la verdad, verdad que niega Avempace pueda provenir de la vía sufí.

Que este tadbir haya sido concebido en directa confrotación con los sufíes prodríamos deducirlo de la condena de que es objeto este mismo término de tadbir, o libre disposición de sus actos por parte del

12 Asín, M., "Tratado de Avempace sobre la unión del intelecto con el hombre", $A l$ Andalus, VII (1942), 45-46 trad.; 21-22 texto árabe.

13 Cfr. al-Kalābādī, al-Taiarruf li-madhab al-tasawwuf, Damasco-Beirut, Dār al Imān, 1407/1986, 112, donde también se aplica al sufí el calificativo de "aislado", mutafarrad, calificativo aplicado también por Avempace al filósofo.

${ }^{14}$ Cfr. El régimen, 42 trad.; 11 texto árabe. Cfr. en la mencionada obra de al-Kalābādīi, 21.

Incluso Avempace dice del filósofo que tiene una fitra fäiqa, naturaleza o talento superior, que es lo que se dice del šayj de una tarìqa, y que, según Avempace, es el talento "con que se adquiere la ciencia especulativa. Tú posees, sin duda, ese talento superior (cfr. M. Asín, "La "carta de adiós"», 65, trad.; 27 texto árabe).

Este calificativo del šayj de una tarīqa lo encuentro citado por 'Abd al-Maŷìd alSagīr en "Al-Minhaŷ al-rušdī wa-ataru-hu fỉ l-hukm 'alà Ibn Rušd 'inda l-magāriba", en $A^{e}$ māl nadwat Ibn Rušd wa-madrasati-hi fi l-garb al-islämi, Casablanca, s.d., 294, a propósito de una cita del Tahäfut de Averroes, ed. Bouyges, 107-108. Si esto es así, tal vez no

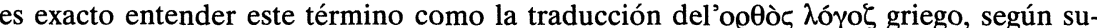
giere S. Van den Bergh en su traducción de esta obra. Cfr. Averroes' Tahäfut al-Tahäfut (The Incoherence of the Incoherence), Cambridge University Press, reprint, 1978, v. II, Notes, 7, p. 8.3. 
hombre, en medios sufíes, ya que en éstos es contrapuesto al de tafwìd, abnegación de la voluntad y delegación de la libre disposición del hombre en Dios:

Han dicho los grandes entre los sufíes: no está la perdición más que en el tadbirr, mientras que la salvación está sólo en el tafwìị ${ }^{15}$.

Por otro lado, ese tadbir de Avempace se refiere fundamentalmente a los actos intelectuales, a las virtudes dianoéticas y no a las éticas, ya que estas últimas, aun reconociendo que son muy valiosas y que son un medio indispensable, "no son éstas el fin último del hombre" ${ }^{16}$. Y ello porque no constituyen su esencia más específica y propia, sino que son virtudes comunes a otras especies animales. Así, comenta que la paciencia es también virtud de la mula o la valentía del león ${ }^{17}$. Esta es toda la valoración que le merece el ascetismo practicado por los sufíes.

Con todo lo expuesto, creo, tenemos suficientes datos en Avempace que apuntan a una clara negación del sufismo y de sus pretensiones ${ }^{18}$.

15 Cfr. Massignon, L., Essai sur les origines du lexique technique de la mystique musulmane, París, 1954, 350, en los extractos del Taiarrufde al-Kalābādī que transcribe.

También tadbir es contrapuesto a tawakkul, o abnegación de la voluntad en Dios, cfr. B. Reinert, Die Lehre vom Tawakkul in der klassischen Sufik, Berlín, 1968, 94-100.

La condena del tadbir es general dentro del sufismo. Cfr. la obra, exclusivamente dedicada a este tema, como se declara en su título, de Ibn 'Ațā' Allāh, al-Tanwìr fi isqāt altadbir, Brockelmann, GAL, v. II, 118; S. v. II, 145-146.

16 Asín, M., "La "carta de adiós"", 64 trad.; 27 texto árabe. En esta minusvaloración de las virtudes éticas se manifiesta Avempace plenamente aristotélico. Cfr. Aristóteles, Etica Nicomáquea, 1178 b.

17 Cfr. Ibid., 63-65 trad.; 26-27 texto árabe.

18 El pensamiento de Avempace ha suscitado problemas desde un principio, pues ya Ibn Tufayl en el prólogo a su citada obra le acusa de oscuridad, ambigüedad, obras inacabadas, etc., por lo que es difícil ver cuál es su verdadera intención y orientación.

En el tema de la consecución del conocimiento superior, el que se obtiene al unirse al Intelecto Activo, es Averroes el primero que le acusa de incongruencia, ya que, dice Averroes (op. cit., 494), en un lugar comenta Avempace que esto es un acto natural y en otro que es un acto sobrenatural.

En efecto, esta contradicción ha motivado opuestas interpretaciones de destacados investigadores. Munk, por ejemplo, interpretó a Avempace como un racionalista total, mientras que Asín, dejándose llevar de estas indicaciones en que Avempace señala que ese conocimiento superior es un don que Dios concede a quien quiere (cfr. M. Asín, "Tratado de Avempace sobre la unión", 47 trad.; 23 texto árabe) concluye con una interpretación más religiosa y fideísta de Avempace (cfr. M. Asín, Ibid., 4).

Ciertamente hay una incongruencia en esto no fácil de salvar. Sólo cabe tener en cuenta por un lado que todo el contexto de la obra de Avempace apunta al esfuerzo hu- 
IBN T⿱ÜFAYL

El punto culminante de esta dialéctica falsafa-sufismo está representado por Ibn Țufayl, quien une armónicamente tanto en su quehacer práctico, su vida, como en su quehacer teórico, su filosofía, ambos aspectos.

En efecto, tenemos, por un lado, que Ibn Țufayl parece haber estado íntimamente relacionado con medios sufíes, pues poseemos una noticia en la que se nos muestra, en estos medios, transmitiendo de otros cómo tuvo lugar la piadosa muerte de Algazel ${ }^{19}$.

Por otro lado, en su quehacer filosófico, aboga por una armonía de sufismo y falsafa, tratando de aunar ambas vías y de que no se vean como excluyentes. Es totalmente revelador a este respecto el prólogo que antepuso a su Hayy ibn Yaqzān, planteándose de lleno esta problemática a partir de las discusiones anteriores.

Allí, a propósito de Avempace, dice que el estado alcanzado por este filósofo fue alto, pero distinto e inferior al conseguido en el éxtasis sufí. Respecto al conocimiento y a la felicidad, los dos puntos en conflicto, los resume con el esclarecedor ejemplo de la diferente situación del ciego de nacimiento, pero muy inteligente, que posteriormente consigue ver. Las diferencias entre antes y después de ver las resume en que el ciego no conoce nada nuevo, pero ahora conoce con una mayor claridad y experimenta un mayor placer al poder ver las cosas que antes sólo conocía por otros sentidos.

Ibn Tufayl, a continuación, sigue hablando de la filosofía de Avicena, cuya filosofía oriental entiende como una filosofía esotérica y a la que pone, junto con la de Algazel, como punto de partida de su propia filosofía.

Ibn Tufayl concibe su filosofía como un proceso hacia el éxtasis al que se accede en un último estadio trascendiendo el discurso racional. Filosofía, por consiguiente, plenamente plotiniana. Al final del prólogo

mano como única causa del conocimiento y de la felicidad del hombre, y, por otro, que hay unos pocos párrafos en que alude a Dios como única causa. ¿Podría entenderse esto último en un sentido general, como que sólo hay unos pocos "privilegiados", "elegidos por Dios", y cita entre ellos a Aristóteles, que consiguen este objetivo o, como observa M. Fakry, A History of Islamic Philosophy, New York, Columbia University Press, 1983, 2. ed., 263, que Avempace restringe ese don divino a los que se han esforzado por conocer, es decir, a los filósofos?

19 Cfr. Abū Ya'qūb Yūsuf ibn Yaḥyà al-Tādilī, Kitāb al-tašawwuf ilà rî̀āl al-taṣawwuf, ed. A. al-Tawfiq, Rabat, 1984, 36. 
nos describe dicho proceso diciendo que ha llegado «a alcanzar la verdad, primero, por el método de la investigación y de la especulación racional" y que ha obtenido "después por la visión intuitiva esa exigua dosis de experiencia mística que ahora gustamos" ${ }^{20}$.

Pero a la filosofía asigna además Ibn Tufayl otra función, y es la de ser un instrumento para expresar esa experiencia extática, expresión que, dado el carácter de inefabilidad del éxtasis, nunca podrá ser perfecta, según reconoce él mismo.

Tras este prólogo, Ibn Tufayl nos pone, mediante un personaje de ficción, Hayy b. Yaqzān, el filósofo autodidacto, un ejemplo práctico de este decurso filosófico $\mathrm{y}$, tras su detallada exposición, nos muestra a Absāl, personaje en el que nos presenta la vía sufí, la vía que accede al éxtasis a partir de la profundización esotérica en la religión exterior, legalista ${ }^{21}$, la cual, a su vez, está representada por otro personaje, Salāmān ${ }^{22}$.

Con todo ello, Ibn Țufayl nos está proponiendo una vía paralela a la del sufismo, una vía erudita, la filosofía de corte plotiniano, que persigue los mismos fines. No es opuesta o excluyente como pretendía Avempace, sino paralela, o incluso convergente, pues el filósofo autodidacto parece ayudarse de ciertas técnicas sufíes, como por ejemplo, la danza circular para acceder al trance extático ${ }^{23}$.

Absāl es el hombre real, el que nace y crece dentro de una tradición religiosa determinada. Lo que Ibn Țufayl añade a este personaje es su filosofía neoplatónica. El hombre ideal, perfecto, es el ilustrado por esa filosofía, el cual ya no necesitará propiamente de las andaderas de una religión histórica, es el caso de Ḥayy ibn Yaqzān. Es más, Ibn Ṭufayl reconoce en su prólogo que el camino normal para llegar a esta plenitud humana es el de la racionalidad, ya que «es muy raro encontrar un

${ }^{20}$ Cfr. 18 texto árabe y 59-60 traducción castellana, en la edición y traducción citadas en la nota 8.

21 En la obra citada en la nota anterior, 140 texto árabe; 104 traducción castellana, se dice que "vestía Absāl una túnica negra de pelo y lana», es decir, que vestía como un sufí.

22 En la caracterización de estos dos personajes, Salāmān y Absāl, Ibn Tufayl parece haber tenido presente lo que de ellos dice Avicena: "Salāmān es una alegoría que te representa a ti mismo y Absāl representa alegóricamente tu grado en el 'irfän (=gnosis o sufismo)". Cfr. en Ibn Sīnā (Avicenne), Livre des directives et remarques (Kitäăb al-'Išārāt wal-tanbihät), trad. et notes par A. M. Goichon, Beirut-París, 1951, 485.

23 Ibid., 116 texto árabe; 92 traducción castellana. 
hombre que sea siempre de vista perspicaz, con los ojos abiertos, y que no necesite de la especulación racional» 24 .

Ibn Țufayl ha intentado, pues, hacer una síntesis de filosofía y sufismo, intento, en cierto modo, similar al de la filosofía desarrollada en el Oriente islámico a partir de Suhrawardī, como ya señaló, aunque muy de pasada, H. Corbin ${ }^{25}$. Sin embargo, a diferencia de la filosofía oriental islámica, esta síntesis de Ibn Țufayl no tuvo continuadores en el Occidente islámico, pues tras él se ahondarán las diferencias en ambos campos, por un lado con Averroes, quien, como veremos a continuación, aun reconociendo la validez del sufismo, lo dejará a un lado, fuera de sus consideraciones, y, por otro, con Ibn 'Arabī, quien desde el sufismo mirará con aires de superioridad y condescendencia el vano, en su opinión, quehacer filosófico.

\section{Averroes}

Averroes, el exponente máximo de la racionalidad en el seno del Islam, además de admitir y defender sinceramente la revelación islámica ${ }^{26}$, manifiesta, con toda claridad, aunque brevemente, su reconocimiento de una fuente de inspiración sufí, advirtiendo, sin embargo, que esta vía no es para todos, sino sólo para unos pocos:

Los métodos de los sufíes no son especulativos, o sea, no están compuestos a base de premisas y silogismos, sino que, según ellos, el conocimiento de Dios y de los otros seres es algo que se encuentra en el alma al despojarla de sus pasiones... Este método, aunque reconocemos su existencia, no se da en la generalidad de los hombres en tanto hombres... pues entonces sería ociosa y vana entre los hombres la vía especulativa, y, por otro lado, todo el Corán es una invitación a la consideración y a la especulación racional 27.

En apoyo de esta cita, que es la más importante que tenemos en Averroes sobre esta cuestión, podemos aducir algunas menciones que parecen apuntar también hacia la inspiración sufí.

24 Ibid., 9 texto árabe; 34 traducción castellana.

25 Histoire de la philosophie islamique, París, 1964, 329.

26 Cfr. Tornero, E., «Religión y filosofía en al-Kindì, Averroes y Kant», Al-Qanțara, II (1981), 89-128.

27 Ibn Rušd, Kašf, en Falsafat Ibn Rušd, ed. Mușțafà 'Abd al-Ŷawād 'Imrãn, El Cairo, 1388/1968, 63 . 
En el Fașl, comentando Averroes el conocido pasaje de la Metafísi$c a$ de Aristóteles de que hay que aceptar el resultado de las investigaciones de las generaciones anteriores pues un hombre solo no podría llegar a ello, añade: «a no ser por revelación divina o algo similar» ${ }^{28}$. La revelación divina, wahy, es la del profeta, y con "algo similar" puede muy bien referirse a la inspiración sufí, ya que ambas, inspiración profética y sufí, son puestas en conexión por Averroes mismo en el Kašf, cuando a propósito del Munqid de Algazel, destaca que este último, hablando de la ciencia de los sufíes

indica que la ciencia sólo se obtiene por la soledad y la meditación, y que esta clase de ciencia es del mismo género que la de los profetas ${ }^{29}$.

Esta conexión entre inspiración profética y sufí no se halla, sin embargo, en el Epitome a los Parva Naturalia ${ }^{30}$, obra compuesta anteriormente al Faṣl y al Kašf, en la que Averroes encuentra muy oportuno, siguiendo una doctrina común a los faläsifa, hablar de la inspiración profética a propósito de la visión en sueños citada por Aristóteles, pero no menciona aquí nada de la inspiración sufí, sino todo lo contrario, insiste en que las ciencias especulativas sólo pueden ser conseguidas a través de las premisas primeras, pues si faltasen éstas sería como si se pudiera correr sin pies y serían vanos éstos entonces. Si hubiera hombres que percibieran estas ciencias especulativas sin aprendizaje, no serían propiamente hombres, sino más bien ángeles.

Resuenan en estos pasajes las citas que he aportado antes de Avempace, y, por ello, es bastante probable que Averroes las haya tenido en cuenta en esta obra ${ }^{31}$.

Si esto es efectivamente así, tenemos que recurrir a la hipótesis de una evolución en el pensamiento de Averroes para encontrar una solución satisfactoria a este diferente proceder.

Que en Averroes hay una evolución, es algo que ha sido puesto muy de relieve, entre otros investigadores, por Ŷamāl al-Dīn al-'Ala-

28 Cfr. Fasl, en la misma obra citada en la nota anterior, 13.

29 Ibid., 100.

30 Cfr. Gaetje, H., ed., Die Epitome der Parva Naturalia des Averroes, Wiesbaden, 1961,88 y 22.

31 Compárese el segundo capítulo del citado Epítome con la primera mitad de El régimen del solitario de Avempace, donde aparecen estas argumentaciones semejantes. Incluso ambos mencionan al califa 'Umar como ejemplo de persona dotada de poderes suprasensibles. 
wī ${ }^{32}$, quien destaca que uno de los indicios de esta evolución es precisamente el progresivo abandono de Avempace por parte de Averroes.

Este abandono podemos constatarlo también en la revisión que hizo Averroes a su Taljị̦ al De anima ${ }^{33}$, revisión en la que suprime un largo párrafo en donde citaba y seguía a Avempace y en donde a propósito de la unión con el Intelecto Activo decía

este estado de unión es el que desean los sufíes, pero es claro que ellos no han llegado nunca, puesto que para llegar a ello es necesario el conocimiento de las ciencias especulativas ${ }^{34}$.

En un primer momento tenemos, pues, que Averroes por influencia de Avempace niega la inspiración sufí, que sólo con posterioridad reconocerá.

Otra consideración que puede aducirse a propósito de este distanciamiento de Avempace es la crítica a la teoría del conocimiento de éste, citada anteriormente, que le hace Averroes en su Comentario Mayor al De anima ${ }^{35}$.

Según esto último, Averroes en una época de mayor madurez parece concebir la génesis del conocimiento no de una manera tan activa por parte del hombre como Avempace, y como él mismo la entendía anteriormente, sino que en esta cuestión, tan ardua y difícil, según reconoce, termina decantándose por un primer origen del conocimiento exterior al hombre que éste recibe y que pone en marcha todo el proceso especulativo. Esta evolución, como reconocen los especialistas no es, por tanto, hacia el aristotelismo, sino más bien hacia el neoplatonismo, un neoplatonismo, pues, más fiel que el de Avempace ${ }^{36}$.

Si de este modo evoluciona el pensamiento de Averroes, es claro

32 al-Matn al-Rušdī. Madjal li-qirä’a ŷadìda, Casablanca, 1986.

33 Cfr. Ibn Rušd, Epitome de anima (Taljịs kitāb al-nafs), ed. S. Gómez Nogales, Madrid, 1985, traducido al castellano por el mismo editor La Psicología de Averoes. Comentario al libro sobre el alma de Aristóteles, Madrid, 1987, 213, nota 399.

34 Al-Ahwānī, A., Taljīs kitāb al-nafs wa-arbå rasāỉl, El Cairo, 1950, 95.

El Taljis al-nafs es del año 1174, anterior a las obras Faṣl(1178) y Kašf (1179) en las que Averroes ya reconoce, como ha dicho, la realidad y verdad del sufismo. Pero este texto editado por al-Ahwānī, según al-'Alawī, op. cit., 85, no es el del Taljịș, sino el del Mujtașar fi l-nafs, una de las primeras composiciones de Averroes, redactada hacia el año 1160.

35 Cfr. supra nota 3.

36 Cfr. Davidson, H. A., op. cit., en los capítulos que dedica al Intelecto Activo y Material en Averroes. 
que le resultaría más fácil admitir la posibilidad de otra vía del conocimiento además de la puramente filosófica. Por ello, teniendo en cuenta todas estas consideraciones, cobra mayores visos de verosimilitud la famosa entrevista que Ibn 'Arabī dice haber tenido con Averroes y en la que éste se muestra contento y satisfecho por haber constatado en Ibn ¿Arabī la realidad y verdad del sufismo. Dice Averroes, según relata Ibn 'Arabī ${ }^{37}$.

Es este un estado psicológico cuya realidad nosotros hemos sostenido con pruebas racionales, pero sin que jamás hubiésemos conocido persona alguna que lo experimentase. ¡Loado sea Dios que nos hizo vivir en un tiempo, en el cual existe una de esas personas dotadas de tal estado místico...!

Aun desde la posición de superioridad en que se sitúa Ibn 'Arạbī en esta entrevista parece latir ahí la sincera preocupación de Averroes por el fenómeno del sufismo, preocupación que desde Avicena está presente en todos los faläsifa.

La misma posición de superioridad sigue manifestando Ibn 'Arabī cuando, a continuación, tras esta entrevista, con motivo del traslado del cadáver de Averroes y de sus libros a lomos de una bestia de carga, improvisa un interrogante y desafiante verso que gravita sobre la racionalidad representada en el mundo islámico por los faläsifa, y que dice así ${ }^{38}$ :

A un lado va el maestro, y al otro van sus libros, mas dime: sus anhelos, ¿viéronse al fin cumplidos?

Hasta qué punto esta problemática que he intentado destacar en la filosofía andalusí estaba presente y preocupaba, al menos en el Islam Occidental, todavía en tiempos de Ibn Jaldūn, podemos constatarlo en la refutación de la falsafa que éste realizó en su Muqaddima ${ }^{39}$, en don-

37 Doy la traducción de M. Asín en El Islam cristianizado. Estudio del "sufismo» a través de las obras de Abenarabi de Murcia, Madrid, 1990, 40. Cfr. texto árabe en Ibn 'Arabī, al-Futūhāt al-makkiyya, ed. 'Uțmān Yahyà, El Cairo, 1392/1972, 373.

38 Cfr. Ibid., trad. de Asín 41; texto árabe citado 373.

39 Cfr. texto árabe en Prolégomènes d'Ebn-Khaldoun, ed. M. Quatremère, París, 1858, v. III, 209-220, y trad. francesa de V. Monteil en Ibn Khaldûn, Discourse sur l'histoire universelle (al-Muqaddima), Beirut, 1968, v. III, 1173-1184.

Cfr. Rosenthal, E. I. J., "Ibn Jaldūn's Attitude to the faläsifa», Al-Andalus, XX (1955), 75-85. 
de precisamente centró su atención en estos dos aspectos de la vía del conocimiento y de la consecución de la felicidad, poniendo frente a frente las pretensiones de los faläsifa y las de los sufíes.

Comenta Ibn Jaldūn que, según los filósofos, la felicidad consiste en conocer las cosas tal como son, y ello se consigue mediante la especulación racional. Hay filósofos, dice, que presumen de obtener aquí, en esta vida, su parte de felicidad, que es la misma que la de los elegidos, la felicidad escatológica, pues llegan a la percepción del Intelecto Activo, uniéndose a él, y todo ello, como resultado de una percepción adquirida a través del estudio.

No sabemos a qué filósofos se refiere exactamente Ibn Jaldūn, pero sí podemos observar que estas ideas coinciden plenamente con lo que hemos visto de Avempace.

En su refutación, niega Ibn Jaldūn estas pretensiones de los fiósofos y dice que los que alcanzan esa felicidad son, en cambio, los sufíes, pero no a través del estudio, como resultado de argumentos y de pruebas lógicas, sino a través de percepciones espirituales, que son directas, sin intermediario de las percepciones físicas de los sentidos o del intelecto, ya que el método de los sufíes consiste en todo lo contrario, en mortificar, anular, estos sentidos e intelecto. Así, obtienen una felicidad que les proporciona una alegría y gozo inefable, que nada tiene que ver con la especulación del filósofo.

Ibn Jaldūn, pues, se inclina por el sufismo en esta discusión, con lo cual podemos concluir que en el Occidente islámico, por un lado, esa primera síntesis de mística y filosofía que se dio en Ibn Țufayl no tuvo continuadores, y por otro, que el sufismo terminó eliminando del horizonte intelectual toda especulación filosófica ${ }^{40}$.

\section{RESUMEN}

Frente al reto del sufismo a la filosofía, sistematizado por Algazel, en cuanto al modo de conseguir el conocimiento y la felicidad del hombre, reaccionan los filósofos andalusíes de diferente modo:

40 Sobre esta misma confrontación, en dos autores del siglo xiI y del Islam Oriental, trata el artículo de W. C. Chittick, "Mysticism versus Philosophy in earlier Islamic History: The al-Ṭūsī, al-Qūnawī Correspondence», Religious Studies 17 (1891), 87-104, trabajo que expone, resumidamente, la doctrina tratada en esta correspondencia, y que se centra sólo en el aspecto del conocimiento. 
Avempace niega totalmente las pretensiones de los sufíes y hace de la filosofía el único medio capaz de dar cumplida satisfacción a todas las potencialidades humanas.

Ibn Tufayl asume la vía sufí dentro de su filosofía, aunando el éxtasis buscado por los sufíes con el éxtasis plotiniano.

Averroes reconoce la validez de la vía sufí, pero sólo para unos pocos. $\mathrm{La}$ vía normal y accesible al hombre inteligente es sólo la filosofía. Filosofía en la que la experiencia del éxtasis no es contemplada.

En el Occidente islámico no tuvo continuidad la síntesis de filosofía y sufismo realizada por Ibn Tufayl, siendo finalmente la filosofía eliminada del horizonte intelectual por el sufismo, fenómeno perfectamente apreciable en Ibn Jaldūn.

\begin{abstract}
The confrontation between Philosophy and Sufism -as systematized by Algazel- as a means for acquiring human knowledge and happiness, provoked differing reactions among Andalusian philosophers:

Avempace totally denied the claims of the sufis and declared Philosophy as the only adequate study for achieving complete satisfaction in all human potentialities.

Ibn Tufayl undertook the Sufi path within his philosophy, combining the ecstasy searched for the sufis with Plotinian ecstasy.

Averroes recognized the validity of the Sufi path, but only for the few. $\mathrm{He}$ believed that the only normal and accesible path for the intelligent man was Philosophy. The experience of ecstasy is not contemplated in his philosophy.

The synthesis of Philosophy and Sufism developed by Ibn Tufayl had no continuity in the western Islamic world, Philosophy being finally eliminated from the intellectual horizon by Sufism, a phenomenon which is perfectly apreciable in Ibn Khaldūn.
\end{abstract}

